\title{
Interpersonal Processes of Couples' Daily Support for Goal Pursuit: The Example of Physical Activity
}

\author{
Berli, Corina ; Bolger, Niall ; Shrout, Patrick E ; Stadler, Gertraud ; Scholz, Urte
}

\begin{abstract}
Little is known about how couples' social support facilitates the pursuit of important goals in daily life. Using an interpersonal perspective, we examined the effects of support provision and receipt on same-day physical activity, and studied the role of partners' joint engagement in activities. One hundred nineteen heterosexual couples reported on target persons' received and partners' provided support across 28 diary days, yielding 2,854 valid days. A dyadic report on couples' joint engagement was obtained from a subset of 88 couples. Target persons' daily activity was objectively assessed via accelerometers. On days with high versus low levels of provided support, target persons' activity was 25 min higher. Support receipt mediated $20 \%$ of this effect. Joint engagement accounted for around half of the effects of provided and received support. Support provision is uniquely linked to goal implementation in everyday life. Joint engagement in activities may be one explanation for how support is facilitated.
\end{abstract}

DOI: https://doi.org/10.1177/0146167217739264

Posted at the Zurich Open Repository and Archive, University of Zurich

ZORA URL: https://doi.org/10.5167/uzh-142317

Journal Article

Accepted Version

Originally published at:

Berli, Corina; Bolger, Niall; Shrout, Patrick E; Stadler, Gertraud; Scholz, Urte (2018). Interpersonal Processes of Couples' Daily Support for Goal Pursuit: The Example of Physical Activity. Personality and Social Psychology Bulletin, 44(3):332-344.

DOI: https://doi.org/10.1177/0146167217739264 


\title{
Interpersonal processes of couples' daily support for goal pursuit:
}

\section{The example of physical activity}

\author{
Corina Berli, University of Zurich \\ Niall Bolger, Columbia University \\ Patrick E. Shrout, New York University \\ Gertraud Stadler, University of Aberdeen, Columbia University \\ Urte Scholz, University of Zurich
}

\begin{abstract}
Author Note
Correspondence should be addressed to: Corina Berli, University of Zurich, Department of

Psychology, Binzmuehlestrasse 14/14, CH-8050 Zurich, Switzerland. Phone: +41 4463572

52,Email: corina.berli@psychologie.uzh.ch
\end{abstract}

Acknowledgements: This project (PP00P1_133632/1) and the first author (P2BEP1_158975) were funded by the Swiss National Science Foundation.

Received date: February 24, 2017

Accepted date: October 2, 2017

This article has been accepted for publication and undergone full peer-review, but has not been through the copyediting, typesetting, pagination and proofreading process, which may lead to differences between this version and the Version of Record. Please cite this article as

DOI: $10.1177 / 0146167217739264$

This article is protected by copyrights. All rights reserved. 
Abstract

Little is known about how couples' social support facilitates the pursuit of important goals in daily life. Using an interpersonal perspective, we examined the effects of support provision and receipt on same-day physical activity, and studied the role of partners' joint engagement in activities. 119 heterosexual couples reported on target persons' received and partners' provided support across 28 diary days, yielding 2854 valid days. A dyadic report on couples' joint engagement was obtained from a subset of 88 couples. Target persons' daily activity was objectively assessed via accelerometers. On days with high versus low levels of provided support, target persons' activity was 25 minutes higher. Support receipt mediated $20 \%$ of this effect. Joint engagement accounted for around half of the effects of provided and received support. Support provision is uniquely linked to goal implementation in everyday life. Joint engagement in activities may be one explanation for how support is facilitated.

Keywords: romantic relationships, social support, goal pursuit, physical activity, daily diary 
Interpersonal processes of couples' daily support for goal pursuit: The example of physical activity

When people face challenging situations in daily life, they often turn to close others such as their romantic partner for help. The perceived availability of social support is widely recognized as having many benefits, including better mental and physical health (e.g., HoltLunstad, Smith, \& Layton, 2010; Kawachi \& Berkman, 2001). In contrast, evidence on the receipt of actual support is mixed (for a review see Rafaeli \& Gleason, 2009). The literature proposes several explanations for the inconsistent findings of received social support. For example, effective support should match an individual's specific needs and goals (Cutrona \& Russell, 1990), or avoid threats to the recipients' self-efficacy (Bolger \& Amarel, 2007).

The effectiveness of social support also seems to depend heavily on the context studied (Uchino, 2009). Many of the mixed findings for actual receipt are based on support in the context of stress or adversity; support processes in the context of promoting life opportunities are much less studied (Feeney \& Collins, 2015). When partners pursue a personal goal (e.g., adopt a healthy lifestyle), support may be less prone to backfire by inadvertent threats to competence or cognitive priming of the unpleasant adversity. The importance of relationship partners for the pursuit of important goals in everyday life has recently been highlighted (Fitzsimons, Finkel, \& vanDellen, 2015; Rusbult, Finkel, \& Kumashiro, 2009). Of special note, Feeney and Collins (2015) proposed a theoretical perspective on thriving through supportive relationships that distinguishes support in response to adversity from support to promote life opportunities. In the latter context support providers can serve as 'active catalysts' in promoting engagement in life opportunities. This can result, among other positive outcomes, in better health behaviors and physical well-being (Berkman, Glass, Brissette, \& Seeman, 2000; Scholz et al., 2016). However, researchers have tended to focus more on support in the context of stress and adversity than on support as a catalyst for approaching life opportunities. 
In the current study we address this gap by examining romantic couples' support for pursuing an important personal goal in daily life, the adoption of regular physical activity. We also aim to understand how possible support effects occur by focusing on support transactions unfolding in a dyadic interaction, and on specific mechanisms of action (cf. Feeney \& Collins, 2015). Using an interpersonal perspective on partner-reported provided and self-reported received support, we examined the extent to which the effect of provided support on daily activity is transmitted via received support. Moreover, we explored whether couples' joint engagement in goal-directed activity (e.g., being physically active together with one's partner) could be a unique interpersonal support behavior, and account for the effects of support.

\section{Adopting Physical Activity in Daily Life: A Context for Social Support}

Regular physical activity has significant benefits for health. It reduces the risk of several diseases including cardiovascular disease, stroke, diabetes, and premature mortality (Mozaffarian et al., 2016). Nevertheless, one in four adults does not achieve the recommended amount of physical activity (World Health Organization [WHO], 2016). The implementation and consistent performance of physical activity in daily life is challenging. Specific support from the romantic partner may provide an important external resource in helping individuals overcome some of the barriers that arise. We define social support as the resources provided by significant others that are intended to facilitate an individual's achievement of a goal or outcome (Heaney \& Israel, 2008). This captures support as a situational factor, referring to actual support behaviors during a specific time frame (i.e., enacted or received support), and is to be distinguished from the perceived availability of help (i.e., perceived support) (Uchino, 2009). Enacted support can be reported from the perspective of the support recipient (i.e. selfreported received support) or the perspective of the support provider (i.e. partner-reported provided support) (Schwarzer \& Knoll, 2007).

People who have actively set a goal (e.g., to become more active), but who have not yet started to implement the intended behavior may particularly benefit from social support as it is 
in line with preexisting goals. Based on Feeney and Collins' (2015) concept of support promoting life opportunities, specific functions of support for people at this stage may include: a) reinforcing motivation and intention strength by validating the goal, revaluing it over competing goals or associating it with complementary goals; b) increasing self-efficacy by appraising the goal as a positive challenge rather than a threat; c) facilitating self-regulatory resources needed for goal implementation by promoting appropriate goal setting, realistic planning, preparatory behaviors, and monitoring; and d) facilitating actual engagement in and maintenance of action by removing barriers. This may be particularly relevant in daily life: Reminding partners to raise goal awareness, offering transportation or taking over chores to free resources for the partner to pursue the goal, or joining in on the effort to pursue the goal. Moreover, providing encouragement and being sensitive and comforting to set-backs can bolster self-efficacy and reduce negative feelings with regard to the goal pursued.

To date, research on enacted support in the context of physical activity is mostly crosssectional (e.g., Marquez \& McAuley, 2006). Some evidence suggests that activity-specific social support is prospectively related to adults' maintenance of physical activity levels (e.g., Kouvonen et al., 2012). However, few studies investigated the effect of actual support instances on action in daily life, using a within-person design. For example, Khan, Stephens, Franks, Rook, and Salem (2013) found that the provision of activity-related spousal support on a given day was predictive of activity levels in patients with Type 2 diabetes that same day. At the same time, research has typically focused on the support recipient, despite the fact that social support is conceptualized as an interpersonal process involving two partners (Feeney \& Collins, 2003, 2015). Recipients' reports of support received are assumed to reflect partners' provided support (e.g., J. L. Cohen, Lakey, Tiell, \& Neeley, 2005), but the reports of support provider and recipient represent independent perspectives. Thus, adopting an interpersonal perspective on support provision and receipt is important to establish a comprehensive understanding of how social support unfolds in a dyadic interaction. 


\section{An Interpersonal Perspective on Support Transactions in Couples}

The functions of support for goal pursuit outlined above are varied and may thus trigger different processes. Some of these processes may require the recipient's attention more explicitly (e.g., reminding the partner of a scheduled activity) than others (e.g., taking over a chore at home). One interesting question that arises from thinking about support as an interpersonal process is: To what extent does support need to be registered by the recipient to effectively contribute to the implementation of a goal? On the one hand, Antonucci (2001) posited that the perception that support was provided, irrespective of whether or not it actually was, may be an important characteristic of support exchanges. In a similar vein, Feeney and Collins (2015) proposed that the effective provision of support should result in the recipient perceiving it as supportive and caring, which will predict outcomes of support. This suggests that the recipient's awareness of support might play a crucial role in how support unfolds its effect. On the other hand, there is some evidence that stress-related support may be particularly beneficial when it is unnoticed by the recipient (i.e. 'invisible support'; Bolger, Zuckerman, \& Kessler, 2000). In their original work, invisible support (i.e., partner reported that support was provided but recipients reported no support was received) was associated with lowest distress in participants facing a major stressor, presumably minimizing the potential negative emotional costs associated with receiving support (Bolger et al., 2000) ${ }^{1}$. Bolger and Amarel (2007) found that visible support was less effective when it communicated a sense of inefficacy to the recipient. Howland and Simpson (2010) described effective invisible support behaviors as being subtle and conversational, blurring the distinction between support recipient and provider roles, and deflecting attention away from the recipient's problem.

Research to date has provided limited insight on what exactly partners do to support each other in implementing a personal goal. There is some evidence that social support may

\footnotetext{
${ }^{1}$ But note that this pattern of results was not consistently replicated (Shrout et al., 2010).
} 
facilitate action by (re)activating intentions, promoting planning and monitoring of the behavior (Molloy, Dixon, Hamer, \& Sniehotta, 2010), as well as strengthening individuals' efficacy beliefs (e.g., Hohl et al., 2016; Rackow, Scholz, \& Hornung, 2015). There is, however, no research on dyadic support behaviors, analogous to research on partners jointly coping with a particular issue or stressor (e.g., common dyadic coping; Bodenmann, 2005). Given the interpersonal nature of support, we argue that jointly implementing goal-directed activity could constitute a unique and effective way to tangibly support goal pursuit. It may facilitate actual engagement by strengthening goal commitment, sparking pleasure, and sparing self-regulatory effort, which oftentimes present momentary barriers for goal pursuit in daily life. Such joint engagement in activities may be particularly relevant in a context of romantic couples where partners' goals are strongly interdependent, as proposed by the transactive goal dynamics theory (Fitzsimons et al., 2015). However, the role of jointly engaging in goal-directed activity within the support process has received little attention so far. Partner's joint engagement may also be particularly relevant for the successful implementation of physical activity goals (i.e., exercising together with the partner). Suggesting a bike ride together, or offering to accompany on a walk seem ideal ways to support the partner to implement his or her activity goals. In line with this, intervention studies suggest that having a sports companion can be effective for action (e.g., Rackow, Scholz, \& Hornung, 2014).

\section{The current study}

In the current study we act on the call by Feeney and Collins (2015) to take a new look at social support as an interpersonal process for positive goal outcomes. Specifically, we focus on daily support transactions in romantic couples who are inactive but pursuing the goal to become physically active, and examine whether and how support is positively linked with the implementation of physical activity in daily life. We strictly apply a within-person (or withincouple) perspective, taking advantage of processed data from an intervention trial (with reports of the main intervention effect and mediating mechanisms at the between-person level being 
published elsewhere; Berli, Stadler, Inauen, \& Scholz, 2016; Berli, Stadler, Shrout, Bolger, \& Scholz, 2017). We advance knowledge in this area in several novel ways: We use an intensive longitudinal design with daily reports on support provision and support receipt to better understand the support process in daily life within dyads. We use accelerometers to provide an objective outcome of the target person's goal implementation in the context of physical activity. Moreover, we consider a dyadic report of joint engagement in goal-directed activity (i.e., being physically active together with the partner) as one potential mechanism of action. Our specific aims are threefold: First, we investigate whether partner-reported provided support predicts higher levels of daily activity. Second, we examine the extent to which the effect of support provision on daily activity is transmitted via support receipt. Third, we examine a dyadic report of joint engagement as one of the specific interpersonal processes of the effects of support provision and receipt for daily activity.

\section{Method}

This study was a secondary analysis of data collected as part of a single-blind randomized controlled trial (ISRCTN15705531) to promote physical activity in overweight and obese individuals (DYACTIC; for detailed information please see Scholz \& Berli, 2014). In brief, the intervention consisted of: 1) an information leaflet with recommendations on health-enhancing physical activity for all participants; 2) the target person setting specific behavioral goals to achieve the recommended physical activity level; and 3) the target person receiving 10 action control text messages delivered in everyday life. Participants of the control group only received the information leaflet, and text messages with a reminder to fill in the end-of-day diary. Compared to target persons of the control group, target persons of the intervention group showed higher achievement of recommended daily activity levels ( $\geq 30 \mathrm{~min}$ of moderate activity performed in bouts of at least $10 \mathrm{~min}$ ) (Berli et al., 2016). The study was funded by the Swiss National Science Foundation (PP00P1_133632/1) and approved by the review board of 
the University of Bern, Switzerland. Below is a concise description of the procedures and measures uniquely relevant for the present paper.

\section{Participants \& Design}

Participants were heterosexual adult couples living in a committed relationship for at least one year $(M=18.8, S D=14.3$ years $)$ and cohabitating for at least 6 months $(M=17.0, S D=$ 14.3 years). Both partners were overweight or obese (Body Mass Index $[\mathrm{BMI}] \geq 25 \mathrm{~kg} / \mathrm{m}^{2}$ ), insufficiently physically active ( $<30$ min per day of at least moderate physical activity), and had the goal to engage in regular physical activity. They were recruited from the community via various channels (e.g., flyers, postings, market research institution). Eligible couples were invited to the lab and randomized as a unit to an intervention ( $n=61$ couples) and control group ( $n=62$ couples). Further, individuals within each couple were randomly allocated to being the target person receiving the intervention (i.e., setting goals and receiving action control text messages), or the participating partner. This random assignment was important due the intervention design with one focal person, and eliminated any systematic bias from assigning this role. Randomization check did not yield significant differences at baseline between the control and intervention group in terms of target persons' gender, age, relationship duration, marital status, education, employment status, body mass index, received social support, and partners' provided social support (all $\mathrm{p}>.05$ ). The desired sample size of 128 couples, based on power needed to test for the main intervention effect, was almost achieved within the project's funding period (for more details on the sampling procedure see Berli et al., 2016). A sample of over 85 couples moreover allowed us to detect between-person correlations between social support and daily activity of at least moderate effect size with 0.80 power (J. Cohen, 1992). No power analysis could be conducted for the within-person correlations, due to lack of information (Bolger, Stadler, \& Laurenceau, 2012). However, with 28 diary days per participant, we expected power to be sufficient to detect within-person associations, and we committed to reporting confidence bounds to indicate the precision of the results. 
The sample comprised 121 target persons $(51.2 \%$ female; $M=46.1$ years, $S D=13.6)$ and their participating partners who completed the in-lab baseline assessments. $69.4 \%$ of the couples were married and $43.0 \%$ had children currently living with them. At baseline, all participating couples provided written consent and completed an online questionnaire. They were instructed to independently fill in an electronic end-of-day diary on a study smartphone within one hour of going to bed for a diary period of 28 consecutive days starting the day after baseline. They were asked not to discuss their answers with their partners. Accelerometers were handed out for the assessment of target person's physical activity across the 28 days. Two target persons were dropped from the present analyses as they did not provide any data on the accelerometer-based outcome measure, leaving a final sample of $N=119$ for the analyses.

Overall, participants showed high diary completion rates $(n=3112$ [93.4\%] for target persons, and $n=3162$ [94.9\%] for partners of 3332 possible diary days). Missed entries were backdated if they were filled in until noon (12pm) the following day. Participants, however, were instructed to complete the diaries during one hour of going to bed to not trigger late entries. Participants who missed entries for more than three consecutive days received a reminder per telephone.

\section{Measures}

Partner-reported support provision. Every evening, partners indicated the extent to which they provided activity-specific social support to the target person that day, with one item each on emotional and practical support (adapted from Bolger et al., 2000), e.g., "Today, I provided emotional support to my partner in terms of his/her physical activity“. Before answering the items, participants were presented with a short description and some examples of emotional (e.g., comfort or encouragement) and practical (e.g., advice or information) support. A mean score was calculated. Response format was 0 (today not at all true) to 5 (today completely true). To facilitate interpretation of results, support was rescaled to a 0 to 1 scale $(0=0,1=0.2,2=$ $0.4, \ldots, 5=1$, etc.), so that one unit represents going from lowest to highest support possible. 
Target person's self-reported support receipt. Analogously, every evening target persons indicated the extent to which they received activity-specific social support from their partners that day, with one item each on emotional and practical support, e.g., "Today, I received emotional support from my partner in terms of my physical activity“. Before answering the items, participants were presented with a short description and some examples of emotional (e.g., comfort or encouragement) and practical (e.g., advice or information) support. A mean score was calculated. Response format was 0 (today not at all true) to 5 (today completely true). To facilitate interpretation of results, support was rescaled to a 0 to 1 scale $(0=0,1=0.2,2=$ $0.4, \ldots, 5=1$, etc.), so that one unit represents going from lowest to highest support possible. Dyadically reported joint engagement. From a subset of participating couples $(N=88)^{2}$, every evening target persons and their partners independently reported on the extent to which they participated together with their partner in physical activity. They were asked to indicate whether they had engaged in seven different moderate-intensity activities (walking, brisk walking, biking, running, fitness gymnastics/dancing, swimming, and team sports) together with their partner that day, and if yes, for how many minutes. Moreover, they could list up to three other activities. All activities were assigned their respective metabolic equivalent [MET] intensity level based on the compendium of physical activities (Ainsworth et al., 2011).

Minutes spent in joint engagement per day were summed for all activities of at least moderate intensity ( $\geq 3.0$ METs) to represent goal-directed activity based with physical activity recommendations. This included most of the additional joint activities that were indicated, as only $1.5 \%$ of all diary entries involved joint activities below moderate intensity (e.g.,

\footnotetext{
${ }^{2}$ Reports on physical activity behavior (including activity together with the partner) in the daily diary was not available for the total sample due to a variation within the control group: Half of the participants in the control group (randomly assigned; $n=31$ ) only completed questions on social-cognitive variables, and did not record self-reported physical activity behavior (see Scholz \& Berli, 2014). We compared the subsample of 88 couples who completed the self-reported physical activity questions in the daily diary with the 31 couples who did not complete these questions in terms of relevant baseline characteristics. No significant differences emerged in terms of age, gender, education, relationship duration, cohabitation, employment status, marital status, body mass index, relationship quality, self-reported physical activity, intentions, action control, received and provided social support (all ps $>.05$ ). Thus, no systematic difference should have been introduced.
} 
housework, cleaning). Reports from target person and partner were highly correlated within couples, and a mean score was thus calculated to represent daily joint engagement as a truly dyadic variable.

Daily activity. Target persons' daily physical activity was assessed with triaxial GT3X+ monitors (ActiGraph, Pensacola, FL) worn at the hip during waking hours. The GT3X+ measures acceleration on three axes, providing a composite measure (i.e., 'vector magnitude'), and is a reliable and valid instrument for measuring physical activity levels (Sasaki, John, \& Freedson, 2011). Only days with at least 10 hours of valid wear time were included in the analyses. Non-wear time was filtered and eliminated from further analysis based on an algorithm of $\geq 90 \mathrm{~min}$ of consecutive zeros in vector magnitude (Choi, Liu, Matthews, \& Buchowski, 2011) ${ }^{3}$. Across the 119 target persons in the final sample, $n=2854$ [83.5\%] of 3332 possible diary days were available, and served as basis for all present analyses. Battery problems encountered by some target persons $(n=16)$ resulting in data loss $(3.8 \%)$ contributed in part to a reduced amount of available diary days. For each participant, the total amount of minutes per day that was spent in at least moderate or vigorous physical activity $(>2690 \mathrm{cpm}$ in vector magnitude; Sasaki et al., 2011) was calculated. For more details on data processing see Berli et al. (2016).

Covariates. At baseline, socio-demographic variables such as gender, age, education, BMI and relationship length were assessed because of their potential influence on physical activity. We moreover created the variables time representing all 28 diary days (centered on the first diary day), weekend day $(0=$ no; 1 = yes $)$, and hours of device wear-time per day (centered around the grand-mean) to be included as covariates in all analyses.

\section{Data Analysis}

\footnotetext{
${ }^{3}$ It is critical to accurately classify wear and non-wear time intervals. Typically an automated algorithm is used to detect and eliminate time with continuous zero readings due to non-wear (e.g., periods of sleeping, showering, forgotten to reattach the monitor etc.) from zero readings due to inactivity (e.g., motionless sitting) (Choi et al., 2011).
} 
We used multilevel modeling to account for the nested structure of repeated measures within individuals. Each predictor variable was first decomposed into individual mean levels across the 28 days (i.e. between-person or Level 2 variance) and the daily fluctuations around these means (i.e. within-person or Level 1 variance). This allowed us to distinguish the withindyadic effects from between-dyad influences (Bolger \& Laurenceau, 2013). The former of these effects represent the dynamics of daily support effects, whereas the latter represents the possible effect of having a typically supportive or unsupportive partner.

To investigate the overall effect of provided support on daily activity (Aim 1), we modeled the target person's activity on a given day as a function of the partner's typical or mean level of provided support (between-person predictor) and the partner's deviation from the typical level of provided support on that same day (within-person predictor). Moreover, we adjusted for time, weekend day, device wear-time, and intervention group, although no differences between the intervention and control groups in minutes of daily activity were previously found (Berli et al., 2016). As recommended by Barr, Levy, Scheepers, and Tily (2013), we specified a maximal random effects structure including random intercept and slopes for all Level 1 predictors ${ }^{4}$. To investigate the extent to which the effect of partner-reported support provision on activity was transmitted via self-reported support receipt (Aim 2), we reran the model 1 described above, adjusting for the target person's received support that same day (withinperson predictor) and the target person's respective mean level of received support across the 28 days (between-person predictor), resulting in model 2a. To examine the role of joint engagement as an interpersonal process of support (Aim 3), we next reran model 2a based on data available only from a subsample of 88 couples reporting on physical activity behavior (including joint engagement with the partner) in the daily diary, which resulted in model $2 \mathrm{~b}$. In

\footnotetext{
${ }^{4}$ A full random effects variance covariance structure (using an unstructured matrix) did not converge. To facilitate numerical convergence, we thus simplified to a more parsimonious variance components (VC) covariance structure on the random effects, where we could estimate the variances, but set the covariance between the random effects to zero.
} 
model 3, we then modeled the target person's activity on a given day as a function of partner's provided support, self-reported received support and couples' dyadically reported joint engagement that same day (within-person predictors) and their respective mean levels across the 28 days (between-person predictors), and compared it with model $2 \mathrm{~b}$ unadjusted for joint engagement. For all analyses, we ran linear mixed models in SPSS 23. We conducted a set of sensitivity analyses to test whether results differed when a) using log-transformed values of daily activity given the skewed distribution of the raw variable, b) including gender, age and relationship length as covariates as they significantly correlated with the outcome, and c) adjusting for levels of daily activity on the previous day. However, results did not change and we therefore reported the more parsimonious models below.

To quantify the indirect effect of provided support on daily activity via received support (Aim 2), we further conducted a within-person mediation analysis (also referred to as lowerlevel or 1-1-1 mediation; Kenny, Korchmaros, \& Bolger, 2003) using Mplus 7. For this purpose, we used within-person centered versions for partner's provided social support (X), self-reported received social support (M), and target person's activity (Y) on a given day (Bolger \& Laurenceau, 2013). We regressed M on X ( $a$ coefficient), Y on both M ( $b$ coefficient) and $X\left(c^{\prime}\right.$ coefficient) allowing for random intercepts and slopes in these withinperson effects. The average total effect across all participants ( $c$ coefficient) is composed of 1$)$ the average direct effect $c^{\prime}, 2$ ) the product of the average $a$ and average $b$ effects, and 3) the covariance of the between-person differences in $a$ and $b, \sigma_{\text {ajbj }}$ (Bolger \& Laurenceau, 2013). Again, we adjusted for time, weekend day and device-wear time.

\section{Results}

Table 1 displays the descriptive statistics and bivariate associations among the main variables. Intra-class correlations, a measure of the degree of dependence of data points (Kreft $\&$ DeLeeuw, 1998), indicated that for the daily activity $43 \%$, for the support measures $36 \%$ - 
$37 \%$, and for joint engagement $25 \%$ of the total variance was due to stable between-person differences.

\section{Overall effect of partner-reported provided social support on daily activity (Aim 1)}

Figure 1 represents the results for partner's provided support on target person's same-day activity (model 1). The level of daily activity on day 0 for the average person (i.e. when all covariates were zero) was 51.97 minutes. As hypothesized, a positive within-person association was observed for the average participant: On days when partners provided high as opposed to low support, target persons engaged in 25.15 more minutes of daily activity, $p<.001,95 \%$ confidence interval (CI) $[18.06,32.23]$. There was significant variation between individuals in their typical level of activity (random intercept), and the extent to which provided support was associated with activity (random slope). The corresponding $S D$ of $23.74(=\sqrt{563.75)}$ for the random slope of provided support indicates that $95 \%$ of the population varies between \pm 46.54 minutes $(=1.96 \times 23.74)$ of the average effect. For complete statistical results see Table $2 .^{5}$

\section{To what extent does support receipt transmit the effects of support provision? (Aim 2)}

Figure 2 summarizes the results from the within-person mediation analysis in Mplus. ${ }^{6}$ For the average participant, partner-reported provided support on a given day predicted greater selfreported received support, $a=0.45, p<.001,95 \% \mathrm{CI}[0.38,0.51]$, and greater self-reported received support predicted more minutes of activity that same day, $b=10.80, p<.01,95 \% \mathrm{CI}$ $[3.94,17.66]$. The indirect effect via received support was significant, $a b=5.08, p<.01,95 \%$ CI $[1.46,8.70]$, and explained $20 \%$ of the overall effect of provided support on daily activity. However, there was also evidence for a direct effect of support provision for the average

\footnotetext{
${ }^{5}$ We also tested for potential differences in the effects between the intervention $(n=58)$ and control group $(n=$ 61) as part of an extensive set of sensitivity analyses. Importantly, no group differences were detected for the within-person effect of provided support. At the between-person level, an interaction with group emerged, $t(116)$ $=2.48, p=.015$. The typical level of provided support (across the 28 days) was not significantly associated with daily activity in the intervention group. In the control group, an unpredicted negative association emerged that depending on the model was either statistically significant or a trend. The interaction at the between-person level does however in no way impact on results at the within-person level.

${ }^{6}$ For the interested reader, corresponding results from the linear mixed model (2a) can be found in Table 2.
} 
participant: Even after adjusting for received support, greater provided support predicted more minutes of daily activity, $c^{\prime}=20.10, p<.001,95 \%$ CI $[12.64,27.57]$. While this effect for provided support is larger in size, it is not reliably different from the effect of received support, $t(116)=1.70, p=.091$

There was considerable variation between individuals in these mediation paths, as reflected by the $S D$ of the average a, b, and c' effect (see Figure 2). Thus, each individual can have a potentially distinct mediation model linking support provision via receipt to activity. Based on the random slopes, we computed the mediated effect of support provision via receipt (ratio of indirect over total effect) for each couple separately. The distribution of these mediated effects suggested that the average effect was fairly representative: For $25 \%, 50 \%$ and $75 \%$ of the sample, support receipt explained up to $10 \%, 17 \%$, and $29 \%$ of the overall effect of support provision on daily activity, respectively.

\section{Joint engagement as interpersonal process of provided and received support (Aim 3)}

Additionally, we examined couples' reports of joint engagement as one possible explanation for the effects of provided and received social support on daily activity, based on available data from a subsample of couples $(N=88)$. One couple did not report any joint engagement across the 28 days. Excluding it from the analyses did however not alter the pattern of results and thus was maintained in the analyses.

Joint engagement reported by both partners was positively associated with daily activity for the average participant: Greater joint engagement on a given day resulted in more minutes of target person's daily activity that same day, $b=0.18, p<.001,95 \%$ CI $[0.13,0.23]$. Over and above the effect of joint engagement, self-reported received support marginally predicted daily activity, $b=6.15, p=.058,95 \%$ CI $[-0.20,12.50]$. The effect was reduced by more than half $(53 \%)$ of the effect from model $2 \mathrm{~b}$ unadjusted for joint engagement $(b=13.14, p<.001$, 95\% CI $[6.31,19.98])$. However, partner's provided support still positively predicted daily activity over and above the effect of joint engagement, $b=12.29, p<.01,95 \%$ CI $[5.08$, 
19.51]. The effect was reduced by less than half (43\%) of the effect from model $2 b$ unadjusted for joint engagement $(b=21.62, p<.001,95 \%$ CI $[13.34,29.91])$. This indicates that the effect of provided support that is unexplained by received support is not entirely accounted for by joint engagement. Again, while the estimate for provided support is larger in size than the estimate for received support after adjusting for joint engagement, we did not find evidence that they were reliably different, $t(85)=1.09, p=.278$. For complete statistical results see Table 2 .

\section{Discussion}

The present study focused on social support for positive goal outcomes in a non-adverse context, consistent with the call by Feeney and Collins (2015). Three specific major findings emerged from our study. First, we found that partner-reported provided support predicted the objectively assessed implementation of daily activity in target persons who had the goal to be physically active. The effect is remarkable, in that on days with high support as opposed to low support, daily activity was by 25 minutes higher. This difference almost equals the recommended amount of health-enhancing physical activity of 30 minutes of moderate activity per day on most days of the week (>150 minutes per week; WHO, 2016). This finding adds to the evidence of a positive association between support from the partner and goal implementation in the context of physical activity (cf. Khan et al., 2013).

Second, we found that only a small portion $(20 \%)$ of the effect of partner-reported provided support on daily activity was transmitted via self-reported received support. There was a moderate association between provided and received support that limited the extent to which the partner-reported support can be explained by explicit acknowledgment of receipt by the recipient. This corresponds with previous research on recipient-provider agreement (J. L. Cohen et al., 2005). Our findings suggest that provided social support does not necessarily need to be registered by the recipient to positively predict daily activity, but has a pronounced independent effect. This stands in contrast with research ascribing the perceptions of recipients 
a critical role in how support relates to psychological and behavioral outcomes (e.g., Vilchinsky et al., 2011).

Third, we found that a dyadic report of joint engagement in activities (subset of 88 couples) accounted for around half of the effects of received and provided support on target person's daily activity. This provides preliminary evidence that joint engagement may indeed be one of the dyadic support behaviors that relate to goal pursuit. Using a distinct behavioral measure based on reports from both target persons and partners provides a unique and innovative dyadic operationalization of joint engagement.

How can we explain the pronounced effect of provider-reported support? It seems important to consider the context of the present study. The sample involved couples where both target persons and partners were overweight or obese, inactive, but had set the goal to engage in regular physical activity. Research suggested that effective support is most likely to stem from a provider who shares similar experiences with the support recipient (Thoits, 1995). This might increase empathic understanding, and lead to a match between the type of support provided and needed (Cutrona \& Russell, 1990). Similarly, Hong et al. (2005) argued that when spouses share an understanding of and commitment to regular physical activity, support may be more likely interpreted as well-intended instead of controlling. In a similar vein, it could be argued that target persons had the possibility to reciprocate support to their partners, creating 'supportive equity' which has been found to be associated with more beneficial outcomes in terms of mood (Gleason, Iida, Bolger, \& Shrout, 2003). The present study seems thus to have created a most favorable context for effective support to occur.

This favorable context might also be relevant to the finding that there were direct effects of partner-reported support when adjusting for recipient support. Some of these effects can be interpreted as what Bolger et al. (2000) called "invisible support". Our study revisits this issue in the context of achieving positive goal outcomes and suggests an additive pattern of provided and received support (i.e., with best outcome for daily activity when both support provision and 
receipt were high). While this does not establish the original invisible support pattern (i.e., with best outcomes when support was provided but not received), it nevertheless reflects an invisible support effect of sorts. It suggests that partners may have effectively engaged in supportive behaviors that the recipients did not code as such. It is in line with previous findings that invisible support as well as support registered by the recipient are both positively related to recipients' long-term goal achievement (Girme, Overall, \& Simpson, 2013).

Interestingly, joint engagement accounted for a substantial amount, but not all of the unique effect of support provision on daily activity. This may imply that there are alternative ways through which activity-specific supportive acts relate to better goal implementation. For some couples, encouraging joint engagement might not be a feasible form of support. Potential barriers could involve that partners have very different fitness levels or preferences for activity routines, or that they have conflicting work schedules that preclude the possibility to jointly implement activity goals. Another barrier could lie in conflicting family situations. For example, cohabiting couples with small children may find it hard to find the time and opportunity to free themselves at home to jointly engage in activities such as running, swimming, or going to the gym. Indeed, couples reporting that at least one of the children was living in the same household (43\%) showed on average lower levels of joint engagement in activities per day (19 minutes) than couples with no children in the same household (31 minutes). For couples facing such barriers, other support forms might become more relevant. Earlier, we have for example proposed that creating opportunities in the home environment (e.g., taking over chores, or watching the children) could be a possible form of effective support. Another possibility to provide support in a rather subtle form is supporting capitalization (e.g., Gable et al., 2006). Capitalization involves that individuals share positive events and successes (e.g., "Yoga class was really fun today", "Today I accomplished a 10k run"). When partners respond actively and constructively ("Wow, that's great"), this has been shown to increase well-being, over and above the effect of the event itself. By celebrating 
successes and accomplishments together, persistence in regular physical activity should be encouraged. Future research should test such an assumption in the context of pursuing health goals. The present results cannot shed light on how exactly joint engagement is encouraged. Was it intended as support and actively proposed from the provider? Or was joint engagement possibly indirectly stimulated, via feelings of closeness that motivated joint goal pursuit. To answer these questions, future studies should use a more fine-grained assessment of social support, for example with open-ended questions on what the support interaction involved. This would provide more insight into the specific support behaviors and whether or not joint engagement is one of the interpersonal support processes.

\section{Strengths \& Limitations}

The present study has several strengths. Collecting independent reports from support providers and support recipients allowed us to examine social support from a truly interpersonal perspective. The daily assessments provided an accurate report of life as it is lived (e.g., reducing retrospection bias; Bolger, Davis, \& Rafaeli, 2003), and allowed us to understand variations in daily social support on physical activity within each couple (i.e., within-person or within-couple level). Moreover, the objective assessment of daily activity via accelerometer is advantageous as it reduces potential bias of self-report measures, and avoids shared measurement variance that may lead to an overestimation of effects (Sallis, Taylor, Dowda, Freeson, \& Pate, 2002). Nevertheless, accelerometers also have some limitations. While the typical placement position at the hip best detects total physical activity volume, it cannot fully account for upper body movement, biking, stair use, and weight lifting (Lee \& Shiroma, 2014). This may have slightly underestimated activity scores of participants performing such activities. At the same time, some activities might require more support than others because they are new and challenging. It is for example plausible that more vigorousintensity activities pose a particular challenge for inactive and overweight participants of the 
present study. However, no systematic bias should be expected in terms of how well such activities are being captured by this methodology.

Some further limitations need to be acknowledged. First, this study addresses partner support that occurs in a non-adverse context of goal pursuit. More specifically, generalizability is limited to romantic partners in which both partners are overweight or obese and have the goal to become more active. The pattern of results may be different in a context in which only one partner is overweight and inactive and needs to achieve a physical activity goal. Such a constellation might make it more likely for support to be perceived as controlling or pressuring (cf. Hong et al., 2005), and result in a less pronounced benefit. Also, it seems likely that for people who do not have the goal to become more active, unintended consequences of support may emerge as a perception of nagging or implicit criticism of the person's goal priorities. Importantly though, social support needs to be differentiated from a more regulatory or control function of relationships (i.e. social control; Lewis \& Rook, 1999), referring to attempts to influence and regulate (health) behavior. Particularly, negative control strategies (e.g., nagging, dropping hints, inducing negative emotions, etc.) have been shown to backfire in terms of psychological well-being and behavioral responses (e.g., Craddock, vanDellen, Novak, \& Ranby, 2015).

Second, assuming that social support is relatively immediate in nature, we tested sameday associations between social support and activity. Sensitivity analyses did not reveal that levels of activity on the previous day impacted these associations. Also, accelerometers did not provide participants with feedback on their activity, which reduces the probability that this should have colored participants' evaluation of support. Nevertheless, the present analysis approach cannot establish temporal order, and results need to be interpreted cautiously in terms of the causal role of the support process. For example, it is also possible that the implementation of activity goals was challenging and thus required more support. Moreover, although we accounted for potential within-person confounders of the associations between 
activity-specific social support and physical activity (e.g., weekend versus weekday), we cannot rule out the possibility that the association is a byproduct of another third process. To rule out such alternative explanations, an experimental setting manipulating partner's support provision in daily life would be needed.

\section{Implications \& Future Direction}

Overall, this study underscores the relevance of expanding the study of support from contexts of life adversity into contexts of promoting life opportunities, and to consider the details of interpersonal process within each supportive process (Feeney \& Collins, 2015). Specifically, our data add to the existing evidence that in a non-adverse context, for most couples support transactions in daily life are a positive form of dyadic exchange and relatively immediately linked with goal implementation. Thus, prompting partners to engage in supportive behaviors in daily life could be used as an effective approach in interventions targeting physical activity goals. This could involve educating partners in the variety of ways support can occur, including subtle or indirect forms of support that may not be perceived as such by the recipient. Moreover, researchers may want to consider the particular opportunity of joint engagement in supporting a close other's goal pursuit. This might also be interesting in that it could bring along benefits for the provider itself (Lewis et al., 2006). For a more comprehensive understanding of the dyadic effects of support in romantic couples, future studies should focus on outcomes in both recipients and providers. Furthermore, it seems important to consider other contexts in which the present findings on the support process may apply. For example, we can assume that the importance of partner support for goal pursuit can be extended to other personal goals, such as learning a language, travelling, or starting a new hobby, etc. Also, we would assume that joint engagement is a relevant support process in other constellations of interdependent, and particularly close and trustful dyads. As such, joint engagement of goal-directed activity is not necessarily limited to romantic relationships, but 
may also occur as part of supportive acts in parent-child, best friend, or even physician-patient dyads, emphasizing collaboration to strengthen goal motivation and pursuit.

Encouraging joint engagement in activities may also involve other goals, such as relationship maintenance. In line with findings that a "we"-approach of couples to overcome a challenge (i.e., common dyadic coping) is associated with better relationship quality (Bodenmann, 2005), it would thus be interesting for future studies to examine whether joint engagement is not only associated with better goal implementation but also with higher intimacy or relationship outcomes. Similarly, joint engagement may also be linked with higher well-being, if perceived as pleasurable. Research on companionship for example revealed that enjoyable dyadic interaction (e.g., participating in shared leisure activities) is associated with better psychological health independently from social support (Rook, 2015).

Importantly, results do not imply that support may never be miscarried or negative (cf. Rafaeli \& Gleason, 2009). The considerable random variation in effects suggests that for some people in the population support might even be counterproductive in terms of daily activity. Even well-intended support can sometimes have unintended consequence when it is not provided in a responsive or sensitive way (Feeney \& Collins, 2015; Rook, 2015). Future research should attend to systematic differences that can explain heterogeneity in support effects across couples, using existing theories and concepts. For example, if the support recipient perceives the support as being responsive or adequate, it is more likely to have the anticipated effect (Feeney \& Collins, 2015). Also, results do not exclude the possibility that support may have dual effects (cf. Gleason et al., 2008), being positively associated with the behavior, but negatively with psychological well-being.

In sum, the results of the present study emphasize that social support in romantic couples are closely linked with goal implementation in daily life. Support provision by the partner seems to occur in subtle forms, and effectively relates to the recipient's physical 
activity without being interpreted as such. Joint engagement is one promising explanation for how support occurs. 


\section{References}

Ainsworth, B. E., Haskell, W. L., Herrmann, S. D., Meckes, N., Bassett, D. R., Jr., TudorLocke, C., .. . Leon, A. S. (2011). 2011 Compendium of Physical Activities: A second update of codes and MET values. Medicine \& Science in Sports \& Exercise, 43(8), 1575-1581. doi: 10.1249/MSS.0b013e31821ece12

Antonucci, T. C. (2001). Social relations: An examination of social networks, social support, and sense of control. . In J. E. Birren \& K. W. Schaie (Eds.), Handbook of the Psychology of Aging (pp. 427 - 453). San Diego, CA: Academic Press.

Barr, D. J., Levy, R., Scheepers, C., \& Tily, H. J. (2013). Random effects structure for confirmatory hypothesis testing: Keep it maximal. Journal of Memory and Language, 68(3), 255-278. doi: 10.1016/j.jml.2012.11.001

Berkman, L. F., Glass, T., Brissette, I., \& Seeman, T. E. (2000). From social integration to health: Durkheim in the new millennium. Social Science \& Medicine, 51(6), 843-857. doi: $10.1016 / \mathrm{S} 0277-9536(00) 00065-4$

Berli, C., Stadler, G., Inauen, J. \& Scholz, U. (2016). Action control in dyads: A randomized controlled trial to promote physical activity in everyday life. Social Science \& Medicine, 163, 89-97. doi: 10.1016/j.socscimed.2016.07.003

Berli, C., Stadler, G., Shrout, P. E., Bolger, N., \& Scholz, U. (2017). Mediators of Physical Activity Adherence: Results from an Action Control Intervention in Couples. Annals of Behavioral Medicine. DOI 10.1007/s12160-017-9923-z

Bodenmann, G. (2005). Dyadic coping and its significance for marital functioning. In T. A. Revenson, K. Kayser \& G. Bodenmann (Eds.), Couples coping with stress: Emerging perspectives on dyadic coping (pp. 33-50). Washington DC: American Psychological Association. 
Bolger, N., \& Amarel, D. (2007). Effects of social support visibility on adjustment to stress: Experimental evidence. Journal of Personality and Social Psychology, 92(3), 458-475. doi: $10.1037 / 0022-3514.92 .3 .458$

Bolger, N., Davis, A., \& Rafaeli, E. (2003). Diary methods: Capturing life as it is lived. Annual Review of Psychology, 54, 579-616. doi: 10.1146/annurev.psych.54.101601.145030

Bolger, N., \& Laurenceau, J. P. (2013). Intensive longitudinal methods: An introduction to diary and experience sampling research. New York: Guilford.

Bolger, N., Stadler, G., \& Laurenceau, J. P. (2012). Power analysis for intensive longitudinal studies. In M. R. Mehl \& T. S. Conner (Eds.), Handbook of research methods for studying daily life (pp. 285-301). New York, NY: Guilford Press.

Bolger, N., Zuckerman, A., \& Kessler, R. C. (2000). Invisible support and adjustment to stress. Journal of Personality and Social Psychology, 79(6), 953-961. doi: $10.1037 / / 0022-3514.79 .6 .953$

Choi, L., Liu, Z., Matthews, C. E., \& Buchowski, M. S. (2011). Validation of Accelerometer Wear and Nonwear Time Classification Algorithm. Medicine \& Science in Sports \& Exercise, 43(2), 357-364. doi: 10.1249/MSS.0b013e3181ed61a3

Cohen, J. (1992). A power primer. Psychological Bulletin, 112(1), 155.

Cohen, J. L., Lakey, B., Tiell, K., \& Neeley, L. C. (2005). Recipient-provider agreement on enacted support, perceived support, and provider personality. Psychological Assessment, 17(3), 375-378. doi: 10.1037/1040-3590.17.3.375

Craddock, E., vanDellen, M. R., Novak, S. A., \& Ranby, K. W. (2015). Influence in Relationships: A Meta-Analysis on Health-Related Social Control. Basic and Applied Social Psychology, 37(2), 118-130. doi: 10.1080/01973533.2015.1011271 
Cutrona, C. E., \& Russell, D. (1990). Type of social support and specific stress: Toward a theory of optimal matching. In I. G. Sarason, B. R. Sarason \& G. R. Pierce (Eds.), Social support: An interactional view (pp. 319-366). New York: Wiley.

Feeney, B. C., \& Collins, N. L. (2003). Motivations for caregiving in adult intimate relationships: Influences on caregiving behavior and relationship functioning. Personality and Social Psychology Bulletin, 29(8), 950-968. doi:

$10.1177 / 0146167203252807$

Feeney, B. C., \& Collins, N. L. (2015). A new look at social support: A theoretical perspective on thriving through relationships. Personality and Social Psychology Review, 19(2), 113-147. doi: 10.1177/1088868314544222

Fitzsimons, G. M., Finkel, E. J., \& vanDellen, M. R. (2015). Transactive goal dynamics. Psychological Review, 122(4), 648-673. doi: 10.1037/a0039654

Gable, S. L., Gonzaga, G. C., \& Strachman, A. (2006). Will you be there for me when things go right? Supportive responses to positive event disclosure. Journal of Personaliy and Social Psychology, 91(5), 904-917.

Girme, Y. U., Overall, N. C., \& Simpson, J. A. (2013). When visibility matters: Short-term versus long-term costs and benefits of visible and invisible support. Personality and Social Psychology Bulletin, 39(11), 1441-1454. doi: 10.1177/0146167213497802

Gleason, M. E., Iida, M., Bolger, N., \& Shrout, P. E. (2003). Daily supportive equity in close relationships. Personality and Social Psychology Bulletin, 29(8), 1036-1045. doi: $10.1177 / 0146167203253473$

Heaney, C. A., \& Israel, B. A. (2008). Social networks and social support. In K. Glanz, B. K. Rimer \& K. Viswanath (Eds.), Health behavior and health education: Theory, Research, and Practice (4th ed., pp. 189-207). San Francisco: John Wiley \& Sons.

Hohl, D. H., Knoll, N., Wiedemann, A., Keller, J., Scholz, U., Schrader, M., \& Burkert, S. (2016). Enabling or cultivating? The role of prostate cancer patients' received partner 
support and self-Efficacy in the maintenance of pelvic floor exercise following tumor surgery. Annals of Behavioral Medicine, 50(2), 247-258. doi: 10.1007/s12160-015$9748-6$

Holt-Lunstad, J., Smith, T. B., \& Layton, J. B. (2010). Social relationships and mortality risk: A meta-analytic review. PLoS Medicine, 7(7), e1000316. doi: 10.1371/journal.pmed.1000316

Hong, T. B., Franks, M. M., Gonzalez, R., Keteyian, S. J., Franklin, B. A., \& Artinian, N. T. (2005). A dyadic investigation of exercise support between cardiac patients and their spouses. Health Psychology, 24(4), 430-434. doi: 10.1037/0278-6133.24.4.430

Howland, M., \& Simpson, J. A. (2010). Getting in under the radar: A dyadic view of invisible support. Psychological Science, 21(12), 1878-1885. doi: 10.1177/0956797610388817

Kawachi, I., \& Berkman, L. F. (2001). Social Ties and Mental Health. Journal of Urban Health: Bulletin of the New York Academy of Medicine, 78(3), 458-467.

Kenny, D. A., Korchmaros, J. D., \& Bolger, N. (2003). Lower level mediation in multilevel models. Psychological Methods, 8(2), 115-128. doi: Doi 10.1037/1082-989x.8.2.115

Khan, C. M., Stephens, M. A., Franks, M. M., Rook, K. S., \& Salem, J. K. (2013). Influences of spousal support and control on diabetes management through physical activity. Health Psychology, 32(7), 739-747. doi: 10.1037/a0028609

Kouvonen, A., De Vogli, R., Stafford, M., Shipley, M. J., Marmot, M. G., Cox, T., . . Kivimaki, M. (2012). Social support and the likelihood of maintaining and improving levels of physical activity: The Whitehall II Study. European Journal of Public Health, 22(4), 514-518. doi: 10.1093/eurpub/ckr091

Kreft, I., \& DeLeeuw, J. (1998). Introducing multilevel modeling. London: SAGE. Lee, I. M., \& Shiroma, E. J. (2014). Using accelerometers to measure physical activity in large-scale epidemiological studies: Issues and challenges. British Journal of Sports Medicine, 48(3), 197-201. doi: 10.1136/bjsports-2013-093154 
Lewis, M. A., McBride, C. M., Pollak, K. I., Puleo, E., Butterfield, R. M., \& Emmons, K. M. (2006). Understanding health behavior change among couples: An interdependence and communal coping approach. Social Science \& Medicine, 62(6), 1369-1380. doi: 10.1016/j.socscimed.2005.08.006

Lewis, M. A., \& Rook, K. S. (1999). Social control in personal relationships: impact on health behaviors and psychological distress. Health Psychology, 18(1), 63-71.

Marquez, D. X., \& McAuley, E. (2006). Social cognitive correlates of leisure time physical activity among Latinos. Journal of Behavioal Medicine, 29(3), 281- 289. doi: $10.1007 / \mathrm{s} 10865-006-9055-6$

Molloy, G. J., Dixon, D., Hamer, M., \& Sniehotta, F. F. (2010). Social support and regular physical activity: Does planning mediate this link? British Journal of Health Psychology, 15(Pt 4), 859-870. doi: 10.1348/135910710X490406

Mozaffarian, D., Benjamin, E. J., Go, A. S., Arnett, D. K., Blaha, M. J., Cushman, M., . . . Stroke Statistics, S. (2016). Heart Disease and Stroke Statistics-2016 Update: A Report From the American Heart Association. Circulation, 133(4), e38-60. doi: 10.1161/CIR.0000000000000350

Rackow, P., Scholz, U., \& Hornung, R. (2014). Effects of a new sports companion on received social support and physical exercise: An intervention study. Applied Psychology: Health and Well-being, 6(3), 300-317. doi: 10.1111/aphw.12029

Rackow, P., Scholz, U., \& Hornung, R. (2015). Received social support and exercising: An intervention study to test the enabling hypothesis. British Journal of Health Psychology, 20(4), 763-776. doi: 10.1111/bjhp.12139

Rafaeli, E., \& Gleason, M. E. (2009). Skilled support within intimate relationships. Journal of Family Theory \& Review, 1, 20-37. 
Rook, K. S. (2015). Social Networks in Later Life: Weighing Positive and Negative Effects on Health and Well-Being. Current Directions in Psychological Science, 24(1), 45-51. doi: $10.1177 / 0963721414551364$

Rusbult, C. E., Finkel, E. J., \& Kumashiro, M. (2009). The Michelangelo Phenomenon. Current Directions in Psychological Science, 18(6), 305-309.

Sallis, J. F., Taylor, W. C., Dowda, M., Freeson, P. S., \& Pate, R. R. (2002). Correlates of vigorous physical activity for children in grades 1 through 12: Comparing parentreported and objectively measured physical activity. Pediatric Exercise Science, 14(1), $30-44$.

Sasaki, J. E., John, D., \& Freedson, P. S. (2011). Validation and comparison of ActiGraph activity monitors. Journal of Science and Medicine in Sport, 14(5), 411-416. doi: 10.1016/j.jsams.2011.04.003

Scholz, U. \& Berli, C. (2014). A dyadic action control trial in overweight and obese couples (DYACTIC). BMC Public Health, 14, 1321-1329.

Scholz, U., Stadler, G., Ochsner, S., Rackow, P., Hornung, R., \& Knoll, N. (2016). Examining the relationship between daily changes in support and smoking around a self-set quit date. Health Psychology, 35(5), 514-517. doi: 10.1037/hea0000286

Schwarzer, R., \& Knoll, N. (2007). Functional roles of social support within the stress and coping process: A theoretical and empirical overview. International Journal of Psychology, 42(4), 243-252. doi: 10.1080/00207590701396641

Shrout, P. E., Bolger, N., Iida, M., Burke, C., Gleason, M. E. J., \& Lane, S. P. (2010). The effects of daily support transactions during acute stress: Results from a diary study of bar exam preparation. In K. T. Sullivan \& J. Davila (Eds.), Support processes in intimate relationships (pp. 175-199). New York: Oxford University Press.

Thoits, P. A. (1995). Stress, coping, and social support processes: Where are we? what next? Journal of Health and Social Behavior, Spec. No., 53-79. 
Uchino, B. N. (2009). Understanding the links between social support and physical health: A life-span perspective with emphasis on the separability of perceived and received support. Perspectives on Psychological Science, 4, 236-255. doi: 10.1111/j.17456924.2009.01122.x

Vilchinsky, N., Dekel, R., Leibowitz, M., Reges, O., Khaskia, A., \& Mosseri, M. (2011). Dynamics of support perceptions among couples coping with cardiac illness: The effect on recovery outcomes. Health Psychology, 30(4), 411-419. doi: $10.1037 / \mathrm{a} 0023453$

World Health Organization [WHO]. (2016). Physical activity. Fact Sheet. Retrieved June 27, 2016, from http://www.who.int/mediacentre/factsheets/fs385/en/ 
Table 1

Descriptive statistics of variables of interest at the between-person and within-person level

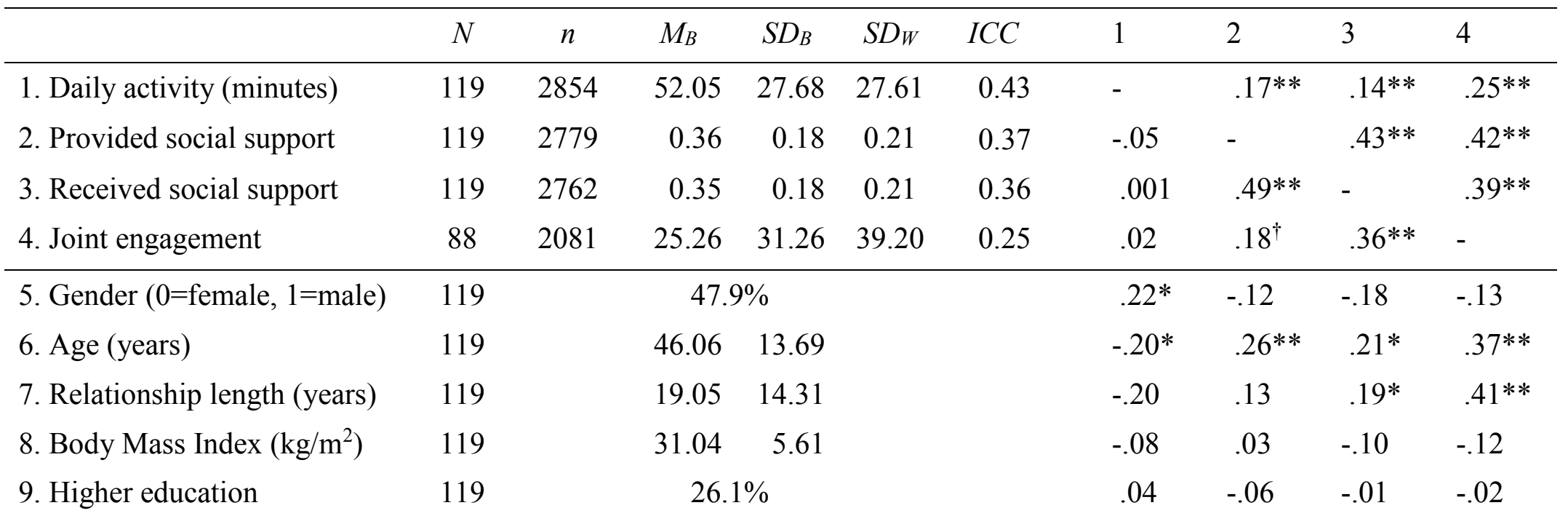

Note. $N=$ number of individuals; $n=$ number of available diary days based on days with valid device wear-time; $M_{B}$ and $S D_{B}$ show the mean and standard deviation of person-specific mean levels (between-person level); $S D_{W}=$ pooled within-person standard deviation (within-person level); ICC = Intra-class correlation; Between-person correlations for variables 1 through 9 are shown below diagonal; Within-person correlations for variables 1 through 4 are shown above diagonal. ${ }^{\dagger} \mathrm{p}<.10,{ }^{*} \mathrm{p}<.05, * * \mathrm{p}<.01$ 


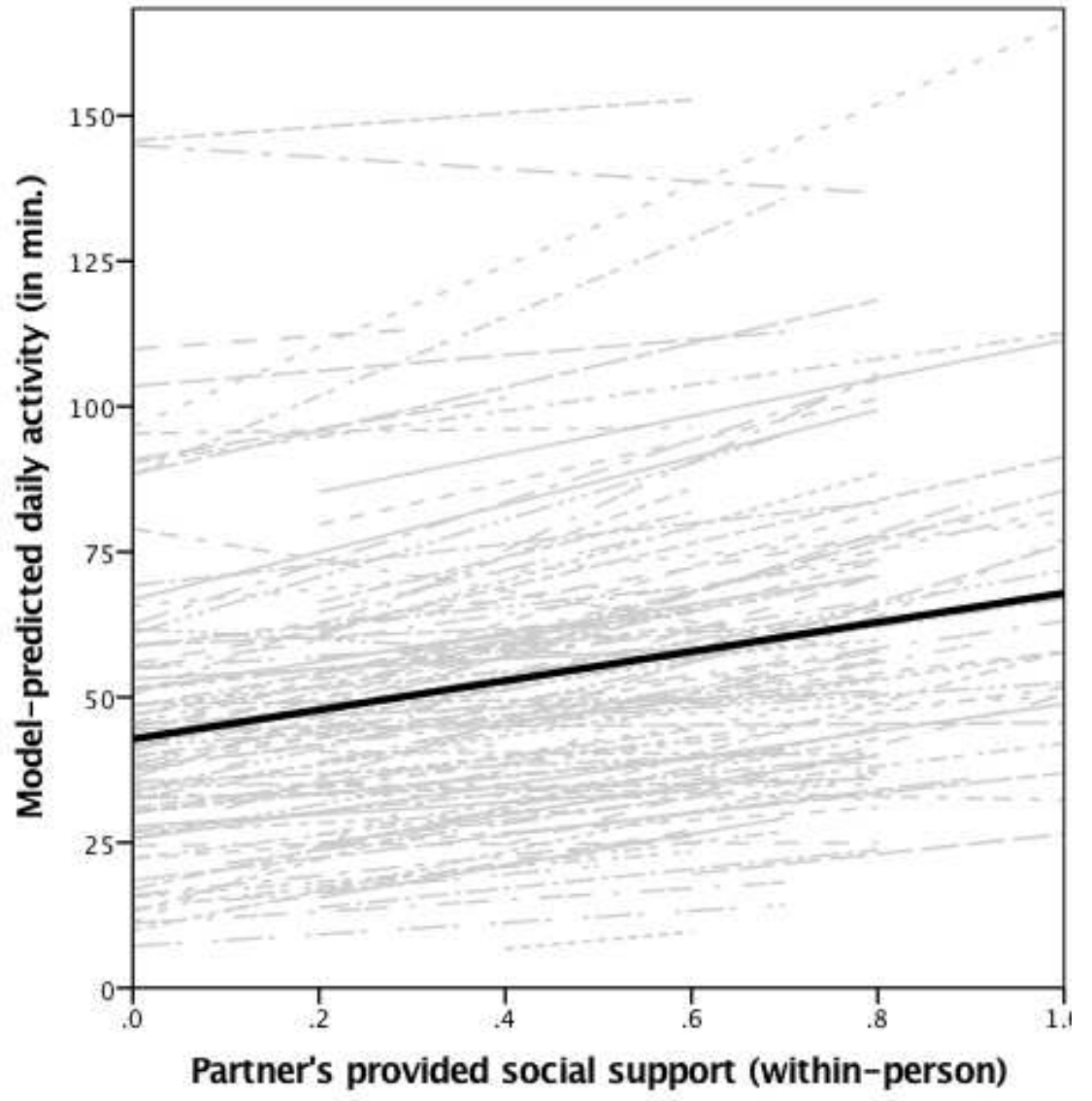

Figure 1 Within-person effect of partner's provided social support on daily activity Note. Thick black line represents average effect (fixed), grey lines represent the random slopes for each individual. 


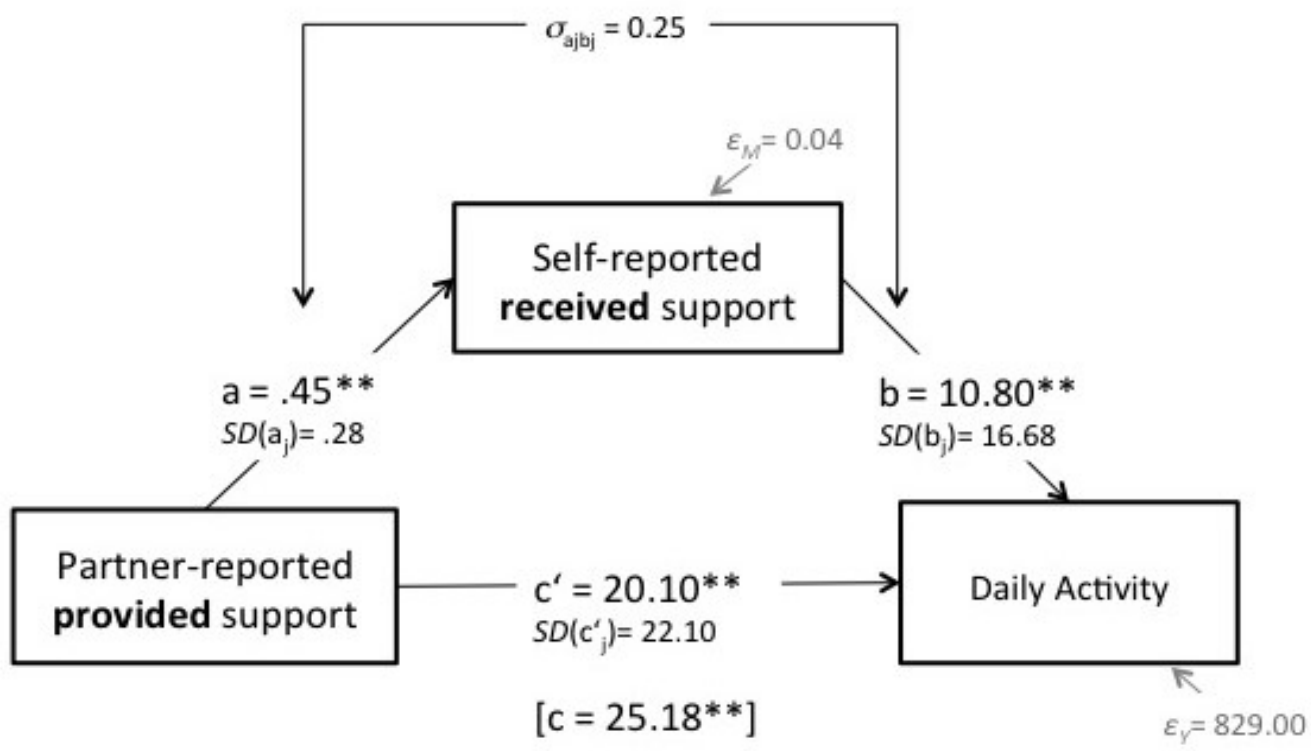

Figure 2 Results for within-person mediation of partner-reported provided support on daily activity via self-reported received support.

Note. Coefficients a, b, and c' represent the average effect across participants. Subscript $j$ denotes the random slope for each individual. $* * p<.01$ 
Table 2 Mixed models with provided support, received support, and joint engagement predicting target persons' daily activity in minutes

\begin{tabular}{|c|c|c|c|c|c|c|c|c|}
\hline \multirow[b]{3}{*}{ Fixed effects } & \multicolumn{4}{|c|}{ Full sample $(N=119)$} & \multicolumn{4}{|c|}{ Subsample with reports on physical activity behavior $(N=88)$} \\
\hline & \multicolumn{2}{|c|}{ Model 1} & \multicolumn{2}{|c|}{ Model 2a } & \multicolumn{2}{|c|}{ Model 2b } & \multicolumn{2}{|c|}{ Model 3} \\
\hline & Estimate & {$[95 \% C I]$} & Estimate & {$[95 \% C I]$} & Estimate & {$[95 \% C I]$} & Estimate & {$[95 \% C I]$} \\
\hline Intercept & $51.97 * *$ & {$[44.55,59.39]$} & $51.51 * *$ & {$[43.96,59.06]$} & $47.59 * *$ & {$[37.47,57.71]$} & $48.69 * *$ & {$[38.47,58.91]$} \\
\hline Within-person provided support & $25.15^{* *}$ & {$[18.06,32.23]$} & $19.81 * *$ & {$[12.35,27.28]$} & $21.62 * *$ & {$[13.34,29.91]$} & $12.29 * *$ & {$[5.08,19.51]$} \\
\hline Between-person provided support & -9.00 & {$[-38.52,20.52]$} & -7.05 & {$[-40.07,25.97]$} & 12.85 & {$[-22.40,48.09]$} & 12.10 & {$[-23.52,47.73]$} \\
\hline Within-person received support & & & $12.58 * *$ & {$[6.01,19.15]$} & $13.14 * *$ & {$[6.31,19.98]$} & $6.15^{\dagger}$ & {$[-0.20,12.50]$} \\
\hline Between-person received support & & & -2.44 & {$[-35.34,30.46]$} & -6.30 & {$[-43.81,31.21]$} & -3.98 & {$[-44.15,36.20]$} \\
\hline Within-person joint engagement & & & & & & & $0.18 * *$ & {$[0.13,0.23]$} \\
\hline Between-person joint engagement & & & & & & & -0.01 & {$[-0.21,0.18]$} \\
\hline Intervention group $(0=$ no, $1=$ yes $)$ & 2.64 & {$[-7.81,13.09]$} & 2.55 & {$[-8.23,13.33]$} & 4.84 & {$[-7.74,17.42]$} & 4.88 & {$[-7.89,17.64]$} \\
\hline Time & -0.01 & {$[-0.16,0.14]$} & 0.03 & {$[-0.12,0.18]$} & 0.11 & {$[-0.06,0.29]$} & 0.10 & {$[-0.07,0.26]$} \\
\hline Device wear-time (in hours/day) & $2.10 * *$ & {$[1.31,2.88]$} & $2.12 * *$ & {$[1.32,2.92]$} & $2.11 * *$ & {$[1.26,2.95]$} & $2.18 * *$ & {$[1.37,2.98]$} \\
\hline Weekend day $(0=$ no, $1=$ yes $)$ & $-3.27^{\dagger}$ & {$[-7.17,0.62]$} & $-3.51^{\dagger}$ & {$[-7.47,0.45]$} & -3.05 & {$[-7.88,1.79]$} & $-6.56 * *$ & {$[-11.44,-1.68]$} \\
\hline Random effects (variances) & Estimate & {$[95 \% C I]$} & & & & & & \\
\hline \multicolumn{9}{|l|}{ Level 2 (between-person) } \\
\hline Intercept & $717.91 * *$ & {$[545.72,944.44]$} & $721.43 * *$ & {$[548.23,949.36]$} & $668.56^{* *}$ & {$[487.08,917.67]$} & $686.23 * *$ & {$[500.62,940.65]$} \\
\hline Within-person provided support & $563.75^{* *}$ & {$[296.24,1072.84]$} & $497.96 * *$ & {$[240.50,949.36]$} & $374.73 *$ & {$[141.53,992.18]$} & 100.64 & {$[8.18,1238.12]$} \\
\hline Within-person received support & & & $196.68 * *$ & {$[48.20,802.57]$} & 45.32 & {$[0.28,7436.56]$} & - & - \\
\hline Within-person joint engagement & & & & & & & $0.02 * *$ & {$[0.01,0.03]$} \\
\hline Device wear-time ${ }^{a}$ & $3.50 *$ & {$[1.35,9.06]$} & $3.65^{*}$ & {$[1.40,9.48]$} & - & - & - & - \\
\hline Weekend day & $227.03 * *$ & {$[140.42,367.09]$} & $231.83 * *$ & {$[142.83,376.30]$} & $275.38 * *$ & {$[164.96,459.71]$} & $295.24 * *$ & {$[181.67,479.82]$} \\
\hline \multicolumn{9}{|l|}{ Level 1 (within-person) } \\
\hline Residual & $823.39 * *$ & {$[777.17,872.36]$} & $814.76^{* *}$ & {$[767.75,864.65]$} & $830.02 * *$ & {$[775.81,888.02]$} & $741.59 * *$ & {$[692.76,793.86]$} \\
\hline Autocorrelation & $0.06^{* *}$ & {$[0.02,0.11]$} & $0.05 *$ & {$[0.01,0.10]$} & 0.03 & {$[-0.02,0.08]$} & $0.07 * *$ & {$[0.02,0.12]$} \\
\hline
\end{tabular}




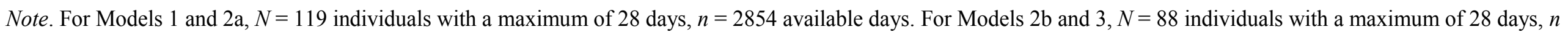

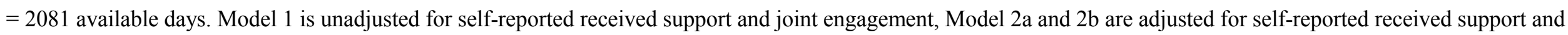

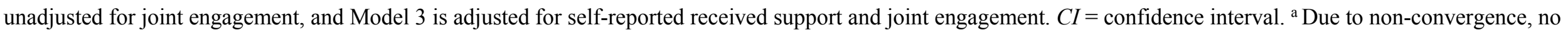

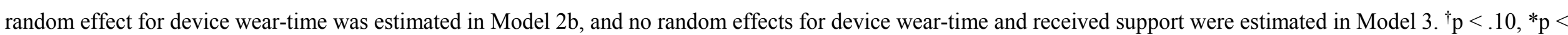
$.05, * * p<.01$ 